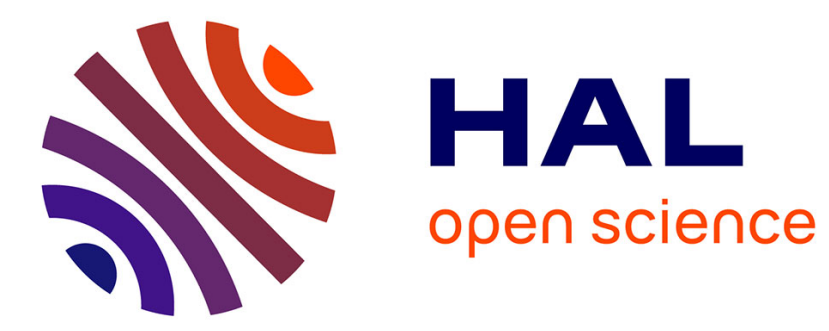

\title{
Void growth and coalescence in a magnesium alloy studied by synchrotron radiation laminography
}

Babak Kondori, Thilo F. Morgeneyer, Lukas Helfen, A. Amine Benzerga

\section{To cite this version:}

Babak Kondori, Thilo F. Morgeneyer, Lukas Helfen, A. Amine Benzerga. Void growth and coalescence in a magnesium alloy studied by synchrotron radiation laminography. Acta Materialia, 2018, 155, pp.80-94. 10.1016/j.actamat.2018.05.026 . hal-01825657

\section{HAL Id: hal-01825657}

https://hal-mines-paristech.archives-ouvertes.fr/hal-01825657

Submitted on 22 Jan 2020

HAL is a multi-disciplinary open access archive for the deposit and dissemination of scientific research documents, whether they are published or not. The documents may come from teaching and research institutions in France or abroad, or from public or private research centers.
L'archive ouverte pluridisciplinaire HAL, est destinée au dépôt et à la diffusion de documents scientifiques de niveau recherche, publiés ou non, émanant des établissements d'enseignement et de recherche français ou étrangers, des laboratoires publics ou privés. 


\title{
Void growth and coalescence in a magnesium alloy studied by synchrotron radiation laminography
}

\author{
Babak Kondori ${ }^{\mathrm{a}, \mathrm{b}}$, Thilo F. Morgeneyer ${ }^{\mathrm{c}}$, Lukas Helfen ${ }^{\mathrm{d}, \mathrm{e}}$, A. Amine Benzerga ${ }^{\mathrm{a}, \mathrm{b}, \mathrm{f}, *}$ \\ ${ }^{a}$ Department of Materials Science $\mathcal{E}$ Engineering, Texas A\&M University, College Station, TX \\ ${ }^{b}$ Center for intelligent Multifunctional Materials and Structures, TEES, College Station, TX \\ ${ }^{c}$ MINES ParisTech, PSL Research University, Centre des Matériaux, CNRS UMR 7633, BP 8791003 \\ Evry, France \\ ${ }^{d}$ Institute for Photon Science and Synchrotron Radiation, Karlsruhe Institute of Technology, D-76131 \\ Karlsruhe, Germany \\ ${ }^{e}$ European Synchrotron Radiation Facility (ESRF), BP 220, F-38043 Grenoble cedex, France \\ ${ }^{f}$ Department of Aerospace Engineering, Texas A\&M University, College Station, TX
}

\begin{abstract}
Damage accumulation is studied in a rolled, partially annealed magnesium alloy by means of synchrotron tomography. To avoid failure by plastic instability and generate an effective damage process zone, round notched bars are deformed up to crack initiation then sheet-like samples are cut out for subsequent tomography observations. The effect of the hydrostatic stress is explored by considering two notch radii. In a given specimen, advantage is taken of the naturally occurring gradients in plastic strain and stress triaxiality to gain insight into the various stages of damage progression, damage-to-fracture transition, as well as crack propagation. The key finding is that damage is quite diffuse in both types of specimens. The observations document extensive void nucleation, growth and coalescence, reminiscent of the most ductile and tough metallic materials. Crack growth is found to be inherently anisotropic. Crack initiation is found to occur predominately at the center of the specimen with a blunt notch, and near the notch root in the specimen with a sharp notch. Quantitative measurements based on about 1000 microvoids and blunted microcracks enable values of void volume fraction and microcrack blunting to be fairly estimated, at macroscopic crack initiation.
\end{abstract}

Keywords: Fracture; Triaxiality; Second-phase particles; Tomographic Imaging; AZ31.

\section{Introduction}

Recent experiments have shown that the notch tensile ductility of wrought AZ31 magnesium alloy exceeds its uniaxial ductility when loaded in the plane of the sheet $[1,2]$. Post mortem fractography showed clear evidence of dimpled fracture in notched specimens, in

\footnotetext{
*Corresponding author

Email address: benzerga@tamu.edu (A. Amine Benzerga)
}

Preprint submitted to Elsevier

April 18, 2018 
contrast to quasi-brittle features in un-notched ones. According to Kondori and Benzerga [2] three factors come into play. First, for metal alloys in general and $\mathrm{Mg}$ alloys in particular, ductile failure occurs due to either damage accumulation (all the way to cracking) or to plastic instability [3]. Most fracture studies in Mg alloys have been reported for prismatic rectangular bars, which are notorious for promoting instability-driven shear failure, with or without a notch [4-7]. In [2] cylindrical specimens were deliberately used to avoid instability induced failure and develop an effective damage process zone. This was achieved successfully in the notched specimens, but not in the smooth ones, which failed in shear. This difference in the overall fracture mode is believed to directly affect the experimentally measured strains to failure.

Another reason for the apparent notch-enhanced ductility comes, according to [2], from the activation of additional deformation systems, induced by stress triaxiality. This mechanism was later corroborated by full field crystal plasticity simulations of notched versus smooth cylindrical bars, in both single crystals [8] and textured polycrystals [9]. The calculations enabled the relative activities of the various deformation systems to be quantified under various triaxial conditions mimicking those encountered in the experiments of Kondori and Benzerga [2]. The results in [8, 9] have shown a higher activity of extension twinning and $\langle c+a\rangle$ pyramidal slip in notched bars, consistent with recent work by Narasimhan and coworkers [10-13]. Finally, in the notched bars, evidence for a decreasing strain-to-failure with increasing stress triaxiality, along with the dimpled character of fracture surfaces, indicated that indeed a damage process zone had developed and that the likely damage mechanisms involved were by void nucleation, growth and coalescence [14]. Furthermore, Kondori and Benzerga [2] pointed out that more void/microcrack blunting occurred in specimens with shallower notches. Although the fracture surfaces of sharply notched bars exhibited brittlelike features, the corresponding strain to failure was still larger than in un-notched bars.

The experimental observations in [1,2] as well as similar ones in a rare-earth alloy [15] constitute therefore a step toward understanding the fundamental, intrinsic mechanisms of triaxiality-dependent damage-induced fracture in $\mathrm{Mg}$ alloys. However, in all of these works the operating damage mechanisms were inferred from post-mortem fracture surface observations or tedious two-dimensional (2D) sectioning. Some evidence of void nucleation at second-phase particles or at twins was discussed, but the experimental techniques that were used did not enable details pertaining to crack initiation and growth to be uncovered.

With the advent of new analytical methods, such as X-ray micro-computed tomography, quantitative microstructural studies have increasingly been carried out in materials science; see $[16,17]$ for reviews. In particular, in situ real-time examination of micro-scale ductile damage processes have become possible in three dimensions [18-22]. Microtomography is advantageous not only because it is, in principle, non-invasive and non-destructive but also because it enables access to data that is far more statistically representative than tedious cross-sectioning techniques. In addition, the possibility of three-dimensional (3D) visualization enables to uncover details about damage processes that would otherwise require much more mental effort.

Although microtomography in materials science has been in use for nearly two decades, only recently have damage and fracture studies been undertaken in magnesium alloys $[6,7$, 
23]. Steglich and Morgeneyer [6] used $1 \mathrm{~mm}$ thick Kahn tear test to study crack extension in AZ31 Mg sheets under monotonic loading. Their microtomography analyses showed no void growth near the extended crack. Fracture took place via shear localization with $45^{\circ}$ zig-zag crack patterns along the through-thickness direction. Nucleation of nano-sized voids and their coalescence via void-sheeting were proposed as the fracture mechanism. The more recent work of Nemcko and Wilkinson [7, 23] also revealed failure by shear localization in thin sheets. As emphasized above, from the purely mechanical point of view, the thin sheet geometries employed in $[6,7,23]$ are conducive to shear banding, a form of instability-driven failure. In addition, anisotropic materials, such as magnesium and aluminum alloys, exhibit a strong propensity for shear localization [24]. Practically, it is important to mitigate against instability-induced failure. However, one cannot access the fundamental damage mechanisms operating in a material such as $\mathrm{Mg}$ when failure is by plastic instability.

The objective of this work is to investigate the mechanisms of post-nucleation damage accumulation and its role in macroscopic crack initiation and growth in $\mathrm{Mg}$ alloys. The investigation is based on ex situ high-resolution synchrotron laminography [25], a microtomographic method particularly adapted to flat specimens such as composite panels [26] or alloy sheet materials $[27,28]$. The idea is to deform round notched bars up to a stage where a damage process zone has developed, based on qualitative information from previous work $[1,2,15]$. Then longitudinal thin sheets that are well suited to laminography are cut from the bars and observed under synchrotron radiation. Furthermore, the effect of stress triaxiality is examined by varying the notch root radius. Advantage is taken of the naturally occurring gradients in mechanical fields to gain insight into the various stages of damage accumulation. However, focus is laid on post-nucleation damage. Although the resolution of the tomography technique used is quite high, there are better techniques for studying nucleation, especially when crystallographic aspects play a key role. In addition, previous studies have revealed two essential mechanisms of void formation in $\mathrm{Mg}$ alloys: twinninginduced microcrack formation [29-31], or cracking of second-phase particles [2, 31-33].

\section{Experimental Procedure}

\subsection{Material and ex situ mechanical testing}

The same material used by Kondori and Benzerga [2] is employed in this study. A 1.25" $(32 \mathrm{~mm})$ thick hot-rolled AZ31B plate in the H24 condition was received from Magnesium Elektron. The three principal directions of the plate are labeled as longitudinal (L), which corresponds to the rolling direction, transverse $(\mathrm{T})$ and short-transverse $(\mathrm{S})$ through the thickness. The material exhibits the usual basal texture, a dual grain size distribution $(\sim 3-$ $4 \mu \mathrm{m}$ for small grains and $\sim 12 \mu \mathrm{m}$ for large ones) and various types of second phase particles $[2]$.

In [2] three types of round notched specimens oriented along $\mathrm{L}$ were used to (i) generate an effective damage process zone; and (ii) investigate the effect of triaxiality on the fracture of $\mathrm{Mg}$ alloy AZ31. The specimens were labeled $\mathrm{RN} \zeta$ with $\zeta$ set by the ratio of root notch radius to the minimum section diameter. A sharper notch induces, upon loading, a higher stress triaxiality (ratio of hydrostatic to deviatoric stress). Here, two of the geometries used 

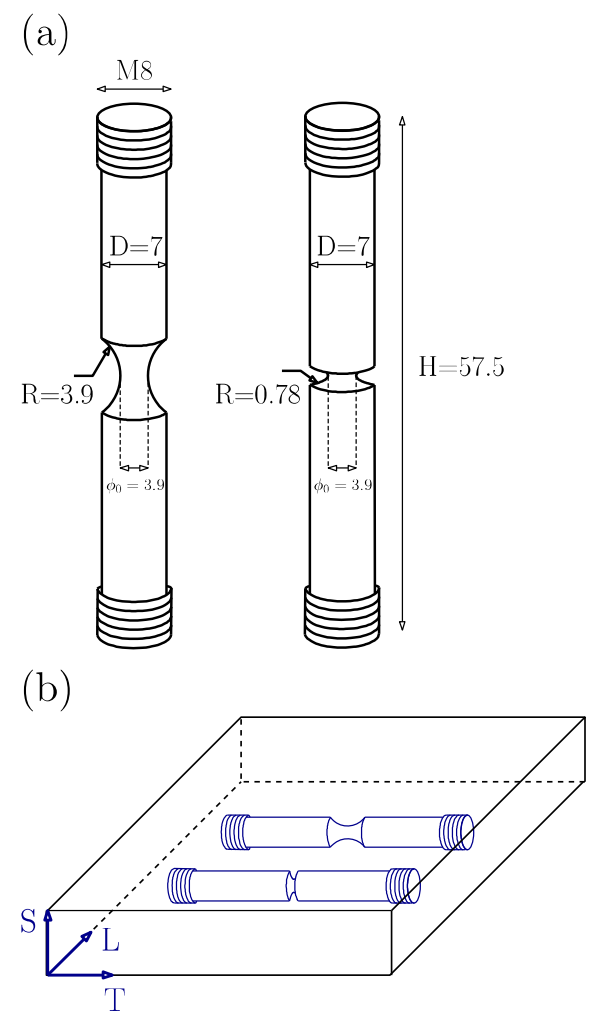

Figure 1: (a) Geometry of the specimens and (b) their orientation in the plate.

in [2], blunt (RN10) and sharp (RN2), were machined along the $\mathrm{T}$ orientation of the plate, Fig. 1. Plastic deformation mechanisms are expected to be similar in $\mathrm{T}$ or $\mathrm{L}$ loading for a given notch acuity. However, the present study enables any potential in-plane fracture anisotropy to be examined.

Taking the notch height as the gauge length, a nominal axial strain rate of $3 \times 10^{-4} s^{-1}$ was imposed. The current diameter along the $\mathrm{S}$ direction was measured using a custom-made radial extensometer, which consists of two knives mounted on an MTS clip-on displacement gage 632.02E-20. For each notch geometry, two specimens were tested on a servo-hydraulic MTS machine (Model 380.50) equipped with a $250 \mathrm{kN}$ load cell. One specimen was deformed to fracture, the other was deformed until a significant load drop had occurred then unloaded. The load drop is a signature of macroscopic crack formation. For reference, un-notched bars were also deformed to fracture at a strain rate of $10^{-3} \mathrm{~s}^{-1}$.

\subsection{Laminography}

A longitudinal section was cut from the bars deformed to incipient cracking, Fig. 2a,b. All sections were flat, about $1.5 \mathrm{~mm}$ thin, parallel to the $\mathrm{T}-\mathrm{L}$ plane, and prepared using electro-discharge machining. The cuts were then shortened using a diamond saw to focus on regions containing the notch. 
(a)

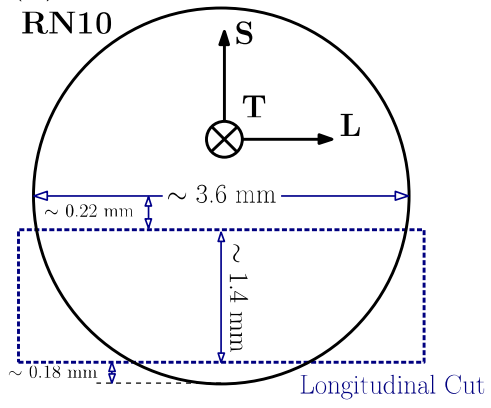

(b)

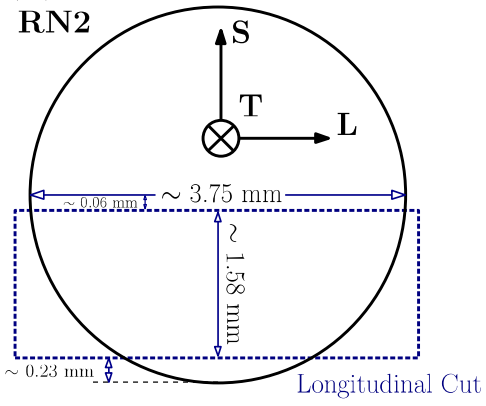

(c)

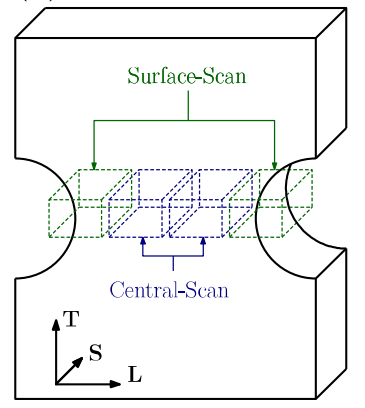

Figure 2: Schematic of the laminography sheet samples. (a),(b) Top views showing the dimensions and relative location of the two samples. (c) Front view showing four overlapping regions of interest labeled as Surface-Scans and Central-Scans.

Here, a particular form of 3D synchrotron imaging, known as laminography, was used. This technique is similar to tomography but adapted to the imaging of regions of interest in flat samples. This allows for easier sample cutting and for analysis of large regions by performing multiple scans. Laminography imaging was performed on the instrument installed by the Karlsruhe Institute of Technology at the imaging beamline ID19 [34] of the European Synchrotron Radiation Facility (ESRF, Grenoble, France) in the conditions described by Morgeneyer et al. [27, 28]. Synchrotron laminography benefits from various contrast modes including propagation-based phase contrast [35] used herein in addition to the conventional absorption employed in conventional laboratory X-ray imaging. Since large source-specimen distances are often used, large sample environments (e.g. mechanical testing devices) can be easily employed for high-resolution imaging without risk of collision during the scanning motion.

Similar to tomography, a series of digital radiographs is acquired while rotating the sample about the laminographic axis [25]. The latter is inclined with respect to the transmitted beam at an angle $0^{\circ}<\theta<90^{\circ}$. With the flat specimen oriented approximately perpendicular to the rotation axis, the average beam transmission can be optimized during the entire laminographic scan. Using filtered back-projection algorithms [36] different planes or complete 3D images with down to sub-micrometer resolution zoomed onto the large specimen can be reconstructed by a single scanning motion.

An inclination angle of the rotation axis of about $25^{\circ}$ with respect to the beam normal was chosen as well as a monochromatic beam of $25 \mathrm{keV}$ X-ray energy. Volumes were reconstructed from 1,500 angularly equidistant radiographs using a microscope-based indirect detector system with $\times 20$ magnification [37] and an ESRF Frelon camera. The exposure time of each projection was $250 \mathrm{~ms}$. The scanned region is $\approx 1 \mathrm{~mm}^{3}$ in volume with a voxel size of $0.7 \mu \mathrm{m}$. The minimum specimen to detector distance is $70 \mathrm{~mm}$ leading to relatively strong edge enhancement due to phase contrast. The resulting strongly contrasted edges facilitate the detection of voids and damage. For easier data handling, all 3D images consisting of 32-bit floating point values were converted into 8-bit gray level 3D images using the same 
linear dependence. As the same affine transformation is performed after reconstruction, the gray level distributions between the images are comparable.

Four scans were carried out on each of the two laminography flat samples to cover its full width, focusing on the region containing the notch minimum cross section. Two of these scans are near the notch root ("Surface-Scans") while the other two cover the central region ("Central-Scans"). The final reconstructed volumes have a size of $2040 \times 2040 \times 2300$ voxels, corresponding to $1428 \times 1428 \times 1610 \mu \mathrm{m}^{3}$. However, only the voxels where all projection directions contribute to the reconstruction exhibit all the directional information available and show similar noise statistics.

\subsection{Quantitative analysis}

To quantify the size and shape of voids at incipient cracking, the in-plane height and width of $\sim 1000$ voids in each laminography flat sample were measured using the image analysis software "ImageJ". All measurements were carried out on 2D micrographs, parallel to the T-L plane at various depth locations across the sample thickness, which coincides with the $\mathrm{S}$ direction. The total areas analyzed were $\sim 31 \mathrm{~mm}^{2}$ and $\sim 36 \mathrm{~mm}^{2}$ for the RN10 and RN2 bars, respectively. The area occupied by each void was then calculated assuming an elliptic shape. The total void area fraction was determined as the ratio of the total area occupied by voids to the total area analyzed, excluding any macro-cracks, as will become evident below. When incipient void coalescence is obvious, the height and width of coalescing voids were determined based on individual estimates of the void boundaries.

\section{Results}

Fig. 3 shows the load versus diameter reduction responses for the two notched bars. A limit load was reached in all specimens, after which significant bar deformation occurred. This is in contrast with un-notched bars, which break rather abruptly after incipient necking, as previously reported for L-oriented specimens [2]. Experiments conducted all the way to fracture were used as reference to estimate deformation and load levels at which each test had to be interrupted. Note that the difference between the limit loads in the two specimens $\left(F_{\max } / A_{0}=310 \mathrm{MPa}\right.$ for the RN10 bar versus $F_{\max } / A_{0}=330 \mathrm{MPa}$ for the RN2 bar) is not as expected based on notch-induced triaxiality effects in isotropic materials [3]. The smaller than expected difference is due to plastic anisotropy, as discussed elsewhere [2, 9].

Fig. 4 shows the strain to fracture, defined on the basis of cross-sectional area reduction as $\varepsilon_{\mathrm{f}}=\left|\ln \left(\phi_{\mathrm{f}}^{\mathrm{S}} / \phi_{0}\right)+\ln \left(\phi_{\mathrm{f}}^{\mathrm{L}} / \phi_{0}\right)\right|$, versus specimen type. Here, $\phi_{\mathrm{f}}^{\mathrm{S}}$ and $\phi_{\mathrm{f}}^{\mathrm{L}}$ refer to the post mortem minimum section diameters along $\mathrm{S}$ and $\mathrm{L}$, respectively. The strain to failure in notched bars may be larger than that in un-notched ones. This trend is consistent with previous findings for L-oriented specimens [2]. In addition, there is a noticeable fracture anisotropy in notched bars with the $\mathrm{T}$ orientation being less ductile. Prasad et al. [11] have reported a negligible anisotropy in fracture toughness in AZ31 (the heat condition was not reported). Given that plastic anisotropy is small in the plane of the sheet [1], the fracture anisotropy may originate from oriented linear clusters of second-phase particles; see $[1,2]$. Such clusters, along with particle shape effects, are known to cause fracture 


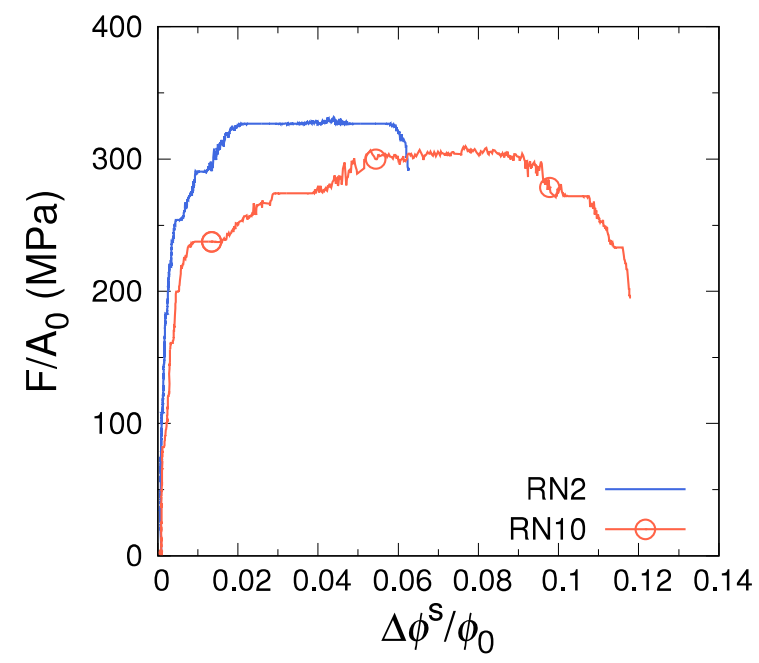

Figure 3: Load normalized by the minimum cross-sectional area, $\left(F / A_{0}\right)$, versus normalized diameter reduction along the $\mathrm{S}$ direction, $\left(\Delta \phi^{\mathrm{S}} / \phi_{0}\right)$, for T-oriented bars.

anisotropy $[38,39]$. The size, shape and spatial distribution of particles is know to depend on heat treatment [40] so that differences with [11] may be explained on that basis if not on differences in stress state associated with the different specimens used.

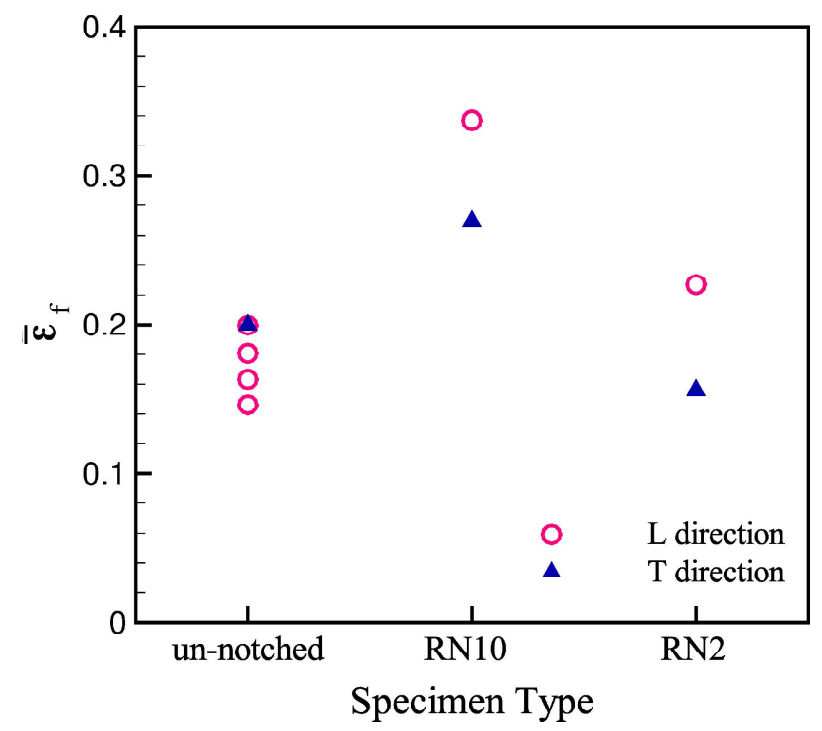

Figure 4: Strain to fracture versus specimen type for T-oriented bars (this paper) and L-oriented ones [2].

In what follows, the results of X-ray laminography are presented as stacks of $2 \mathrm{D}$ sections in the $\mathrm{T}-\mathrm{L}$ plane of reconstructed $3 \mathrm{D}$ data. Features of interest are identified by their shape and contrast. The Mg-rich matrix appears gray. White features represent second phase particles with levels of contrast varying from one particle to an other depending on constituent elements. Particles with heavy elements, such as Mn and Zn, appear brighter [2]. Voids and cracks appear black with the contrast depending on depth of location. 


\subsection{State of damage in the RN10 specimen}

The bar with a shallow notch (RN10 specimen) was deformed to a nominal strain of $\Delta \phi_{S} / \phi_{0}=0.12$. Representative images from the central scans, Fig. 5, show that the state

(a)

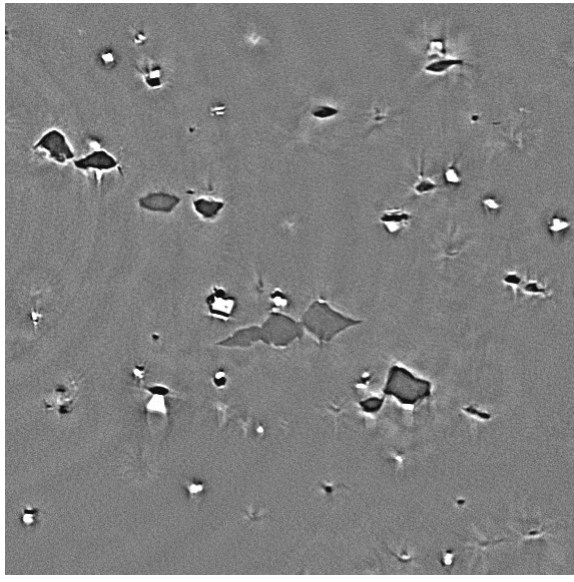

(b)

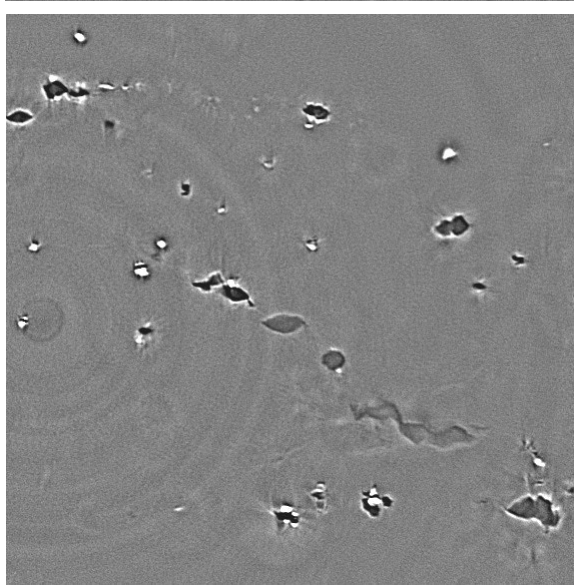

(c)

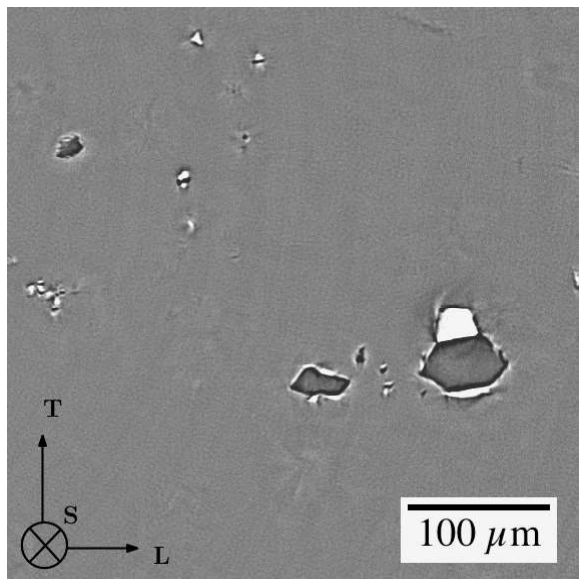

Figure 5: Reconstructed micrographs of the Central-Scans (see Fig. 2) showing diffuse damage in the RN10 specimen deformed to $\Delta \phi_{S} / \phi_{0}=0.12$. 
of damage is quite diffuse. Multiple voids can be observed at various stages: nucleation at second-phase particles, e.g. Fig. 5c, growth and several coalescence events. Freshly formed

(a)

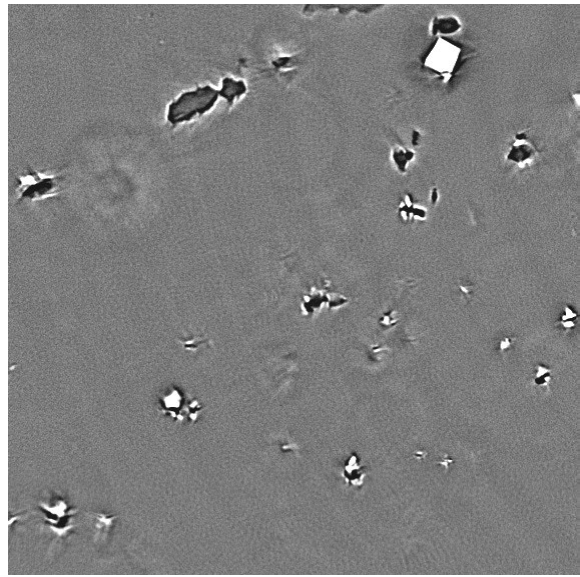

(b)

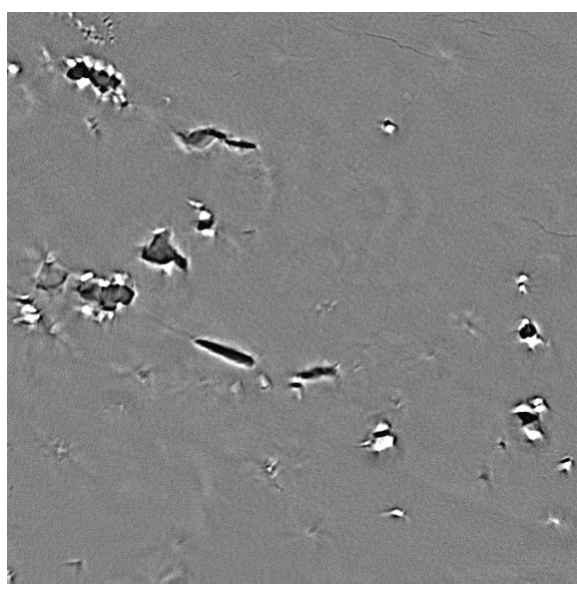

(c)

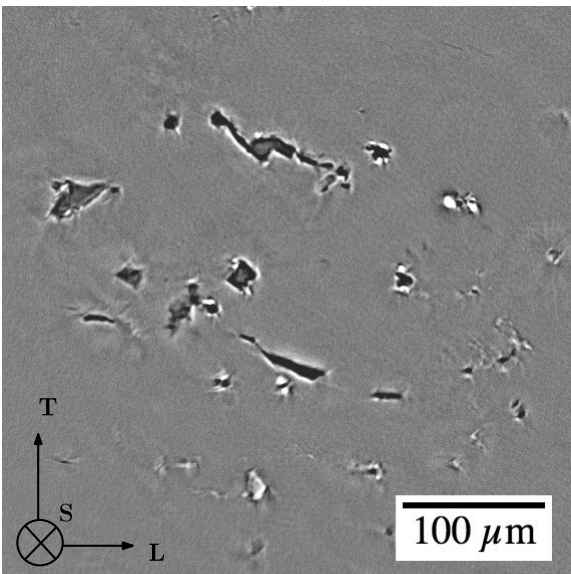

Figure 6: Reconstructed micrographs of the Surface-Scans showing diffuse damage in the RN10 specimen.

voids are rather flat, for example due to "one-sided" particle-matrix decohesion, Fig. 5a. Flat micro-voids are hereafter referred to as micro-cracks. Most other voids appear well 
blunted. Void coalescence by internal necking is clearly seen in Fig. 5a. As will become evident later, this state of diffuse damage coexists with multiple macroscopic cracks.

By way of contrast, the state of damage near the free surface, Fig. 6, mostly manifests as micro-cracks, which have not blunted as much as in the center of the bar (compare with Fig. 5). Differences in the extent of damage between surface and central regions are common in ductile metallic materials [3], and are attributed to differences in levels of stress triaxiality and plastic strain. In general, the stress triaxiality is larger at the center whereas the maximum plastic strain is initially at the notch root but gradually shifts towards the center upon sufficient straining [39]. On this basis alone, it is not surprising that more void growth/blunting has occurred in the central region of the specimen. Another possible factor in explaining differences in damage states between the center (Fig. 5) and the notch root

(a)

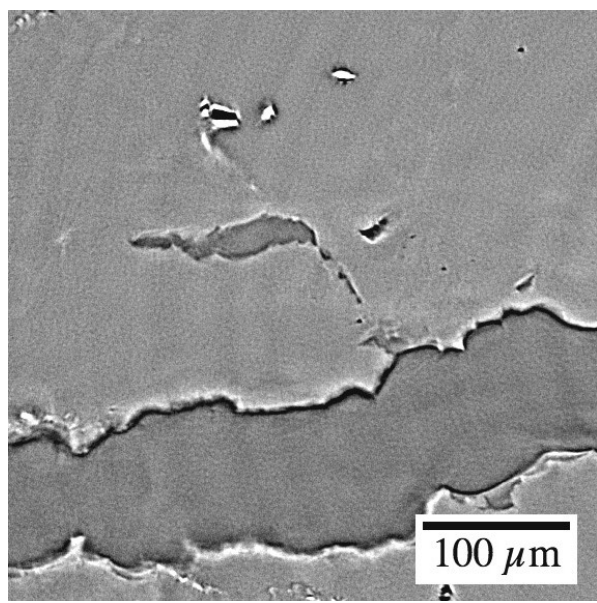

(c)

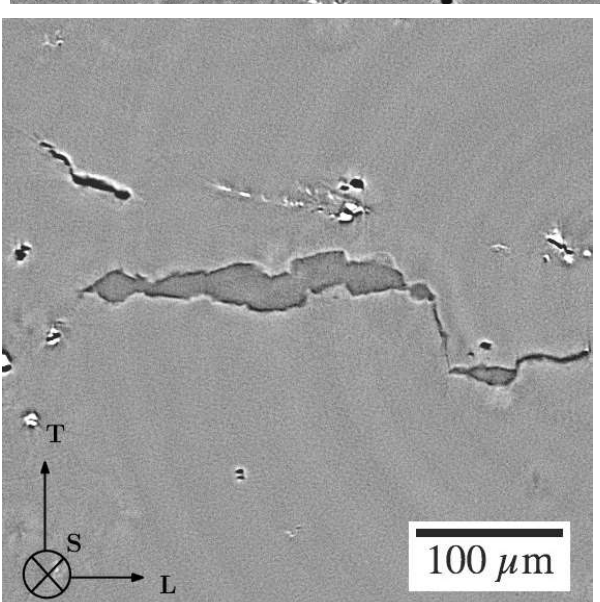

(b)
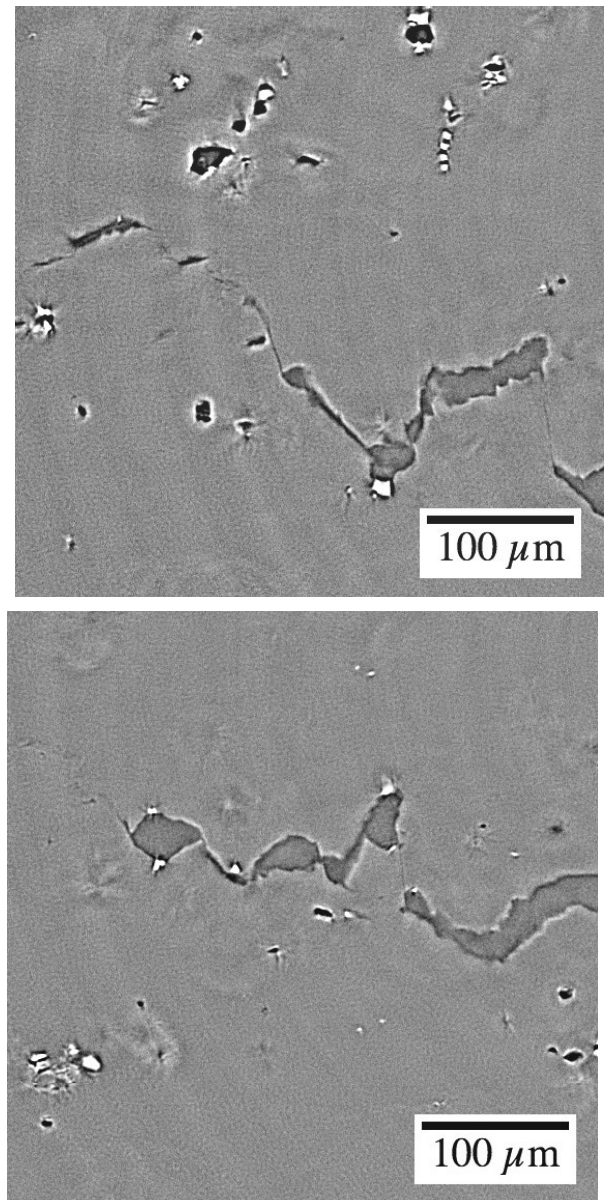

Figure 7: Void/microcrack link-up via micro-scale localization in the Central-Scans of RN10 specimen.

(Fig. 6) is the role of plastic anisotropy [9]. In addition, any twinning-induced cracks would also appear as microcracks the blunting of which remains to be analyzed. Whether some of the microcracks observed in Fig. 6 have initiated on twins would be difficult to ascertain based solely on tomography images. 
When neighboring voids/microcracks reach a critical configuration they often link-up by a micro-scale localized deformation that leads to internal necking of the intervoid ligament; see e.g. $[41,42]$ for analysis of the phenomenon. Such instances were shown in Fig. 5a. This process is essential in formation of macroscopic cracks. One such macroscopic crack is analyzed further in Fig. 7. At the center of the crack, Fig. 7a, the crack opening is quite large $(\sim 100 \mu \mathrm{m})$. This indicates ductile behavior. The crack most likely grew by subsequent "swallowing" of previously formed voids of the kind shown in Fig. 5. In general, observation of the crack tips, Fig. 7b,d, is quite informative about the crack growth process, which is driven primarily along the L direction. Crack linking may also occur by shear. As there are multiple initiation sites, either of fully formed macro-cracks or large voids, the main crack may link up with voids ahead of its tip (Fig. 7d) or with another crack (Fig. 7a-c) by shear. This linkage by a shear process obviously depends on the relative spatial positioning of the coalescing voids and cracks.

A 3D rendering of a macrocrack formed by link-up in shear of two shorter ones is shown in Fig. 8. A 2D trace of the same crack was shown in Fig. 7c. The figure shows a $25 \mu \mathrm{m}-$ thick slice of the material observed in the central scans. It is clear that the growth of each

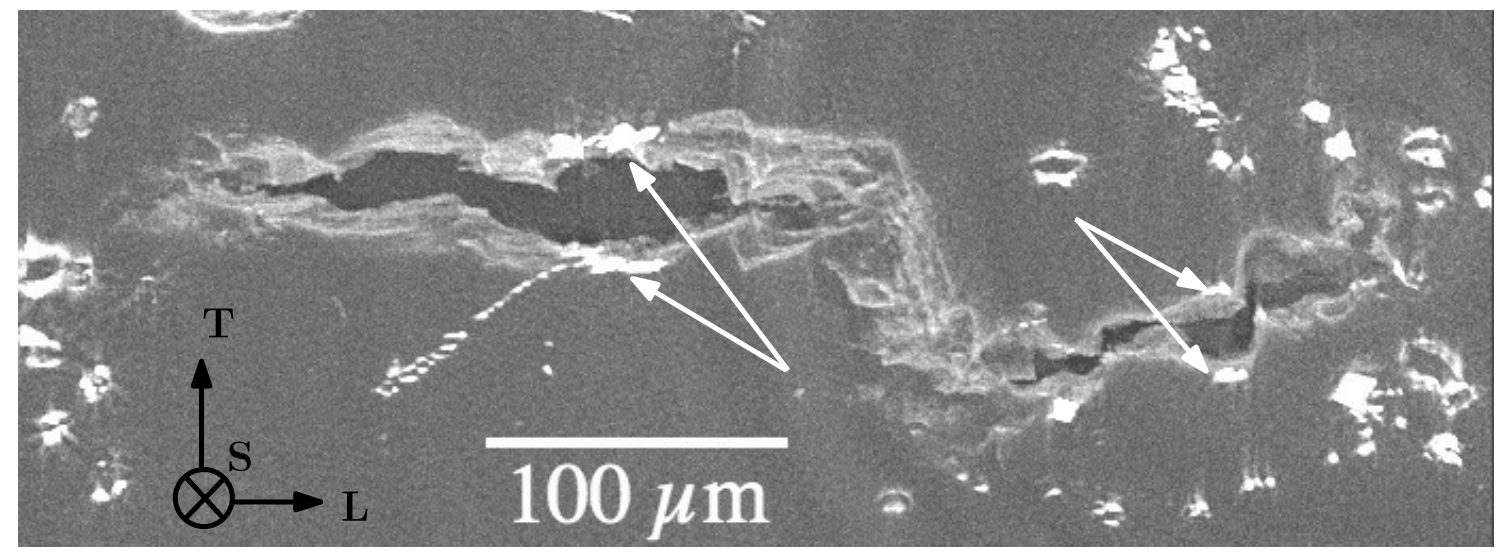

Figure 8: 3D view of two macrocracks linking up in shear. The projected region covers a $486 \times 169 \mu m^{2}$ area and has a thickness of $\sim 25 \mu \mathrm{m}$.

macrocrack proceeds essentially by coalescence along L, before the two macrocracks, which must have separately formed at two distinct heights, connect in shear. Note that the high particle density in Fig. 8 is only apparent because the particles may lie in different planes. Voids in the vicinity of the large macrocrack have not grown much. It is likely that formation of the macrocrack elastically unloaded nearby voids and halted further growth. On the other hand, it is rather clear that the largest void involved in either macrocrack has initiated on a second-phase particle, as marked by white arrows in Fig. 8.

Quite a few macrocracks of the type shown in Fig. 8 form near the center of the specimen. However, fewer macrocracks form close to the notch root. These can be observed in surface scans, an example of which is shown in Fig. 9. The inset in Fig. 9a schematically shows the approximate locations of all sections. The free surface eventually appears left (Fig. 9e,f). 
(a)

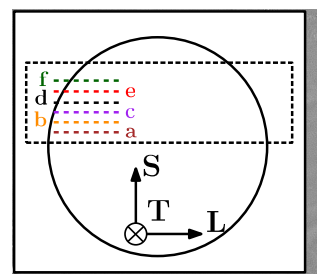

(b)

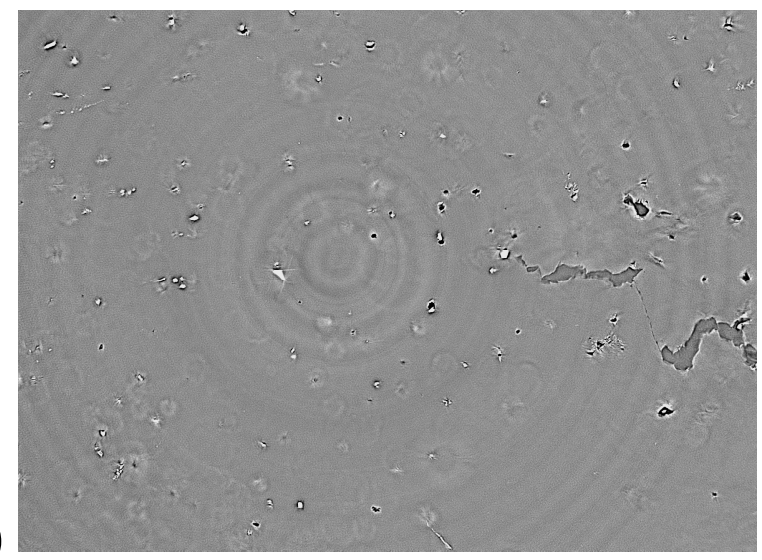

(c)

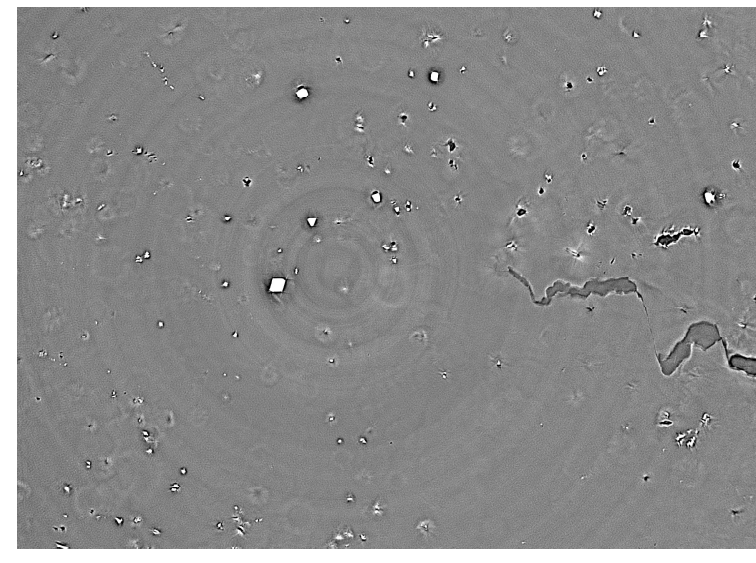

(d)

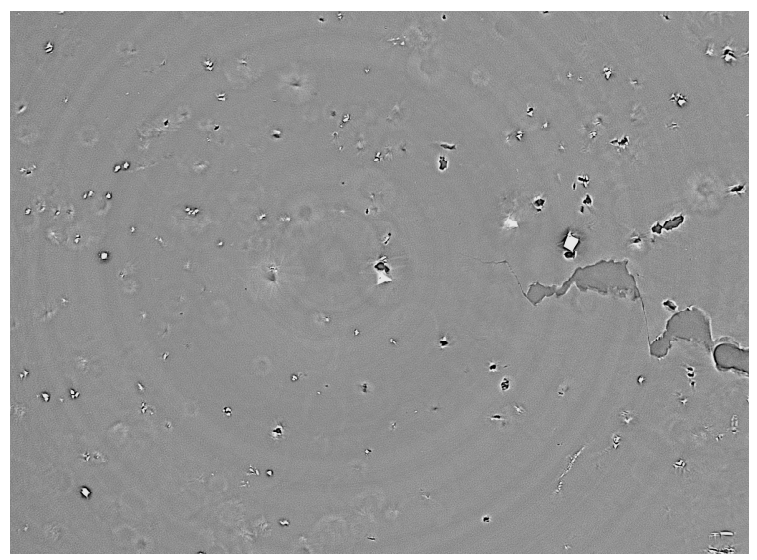

(e)

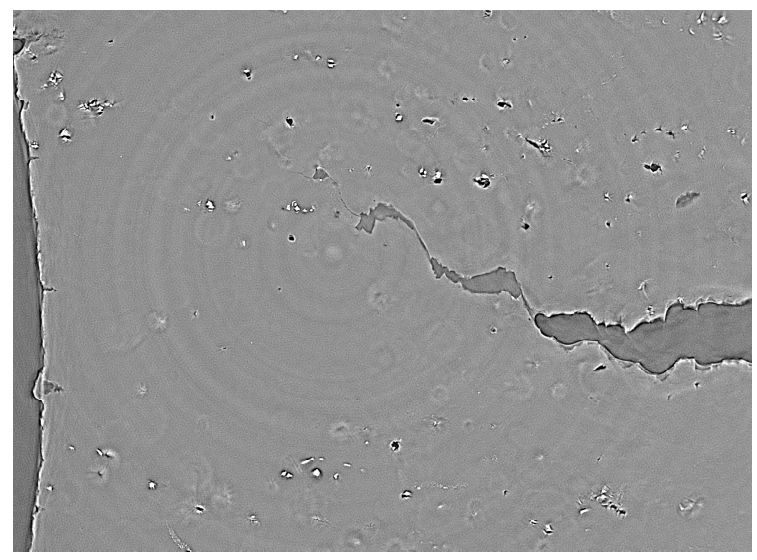

(f)

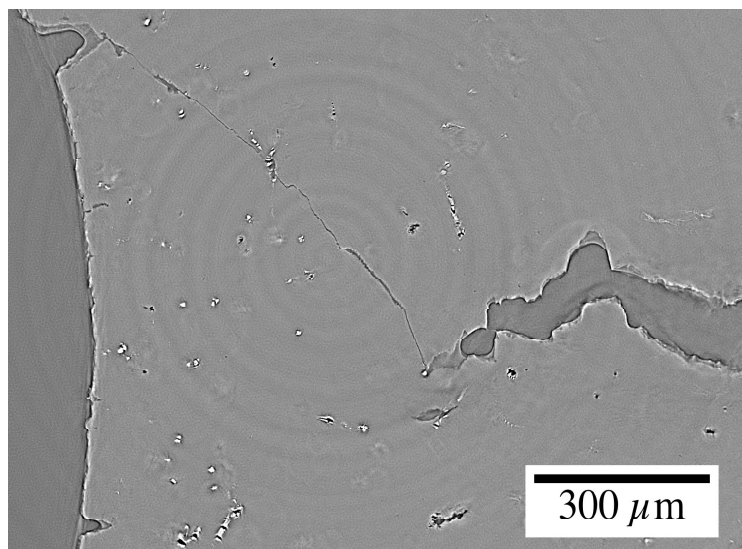

Figure 9: Reconstructed micrographs of a macrocrack in a Surface-Scan of RN10 specimen. From (a) to (f), the micrographs are obtained from locations that are closer to the free surface along the S direction. The inset in (a) illustrates the location of $\mathrm{T}-\mathrm{L}$ projections in the top-view of the bar.

From Fig. 9, previously stated facts are reinforced: (i) the large number of second-phase particles and their role in void nucleation; (ii) isolated void coalescence events, e.g., Fig. 9c (also see Fig. 5a); (iii) crack growth along the L direction by void coalescence with the crack tip, e.g., Fig. 9e; (iv) eventual link-up of independently formed macrocracks by micro-shear, 
e.g., Fig. 9b. In addition, Fig. 9 highlights (v) the formation of a shear lip (Fig. 9f); and (vi) an apparent brittleness at the crack tip (zoom into the tip in Fig. 9d), as noted by some authors. However, the latter observation is misleading. Indeed, the 3D picture becomes rather clear when examing the sequence (c) through (e): the seemingly brittle crack seen in (d) is simply the trace of link-up in shear between different parts of the same macrocrack. Also note that the shear lip in Fig. 9f connects the main crack to an incipient surface crack. Kondori and Benzerga [2] discussed the formation of surface cracks that are seen here as protrusions on the free surface.
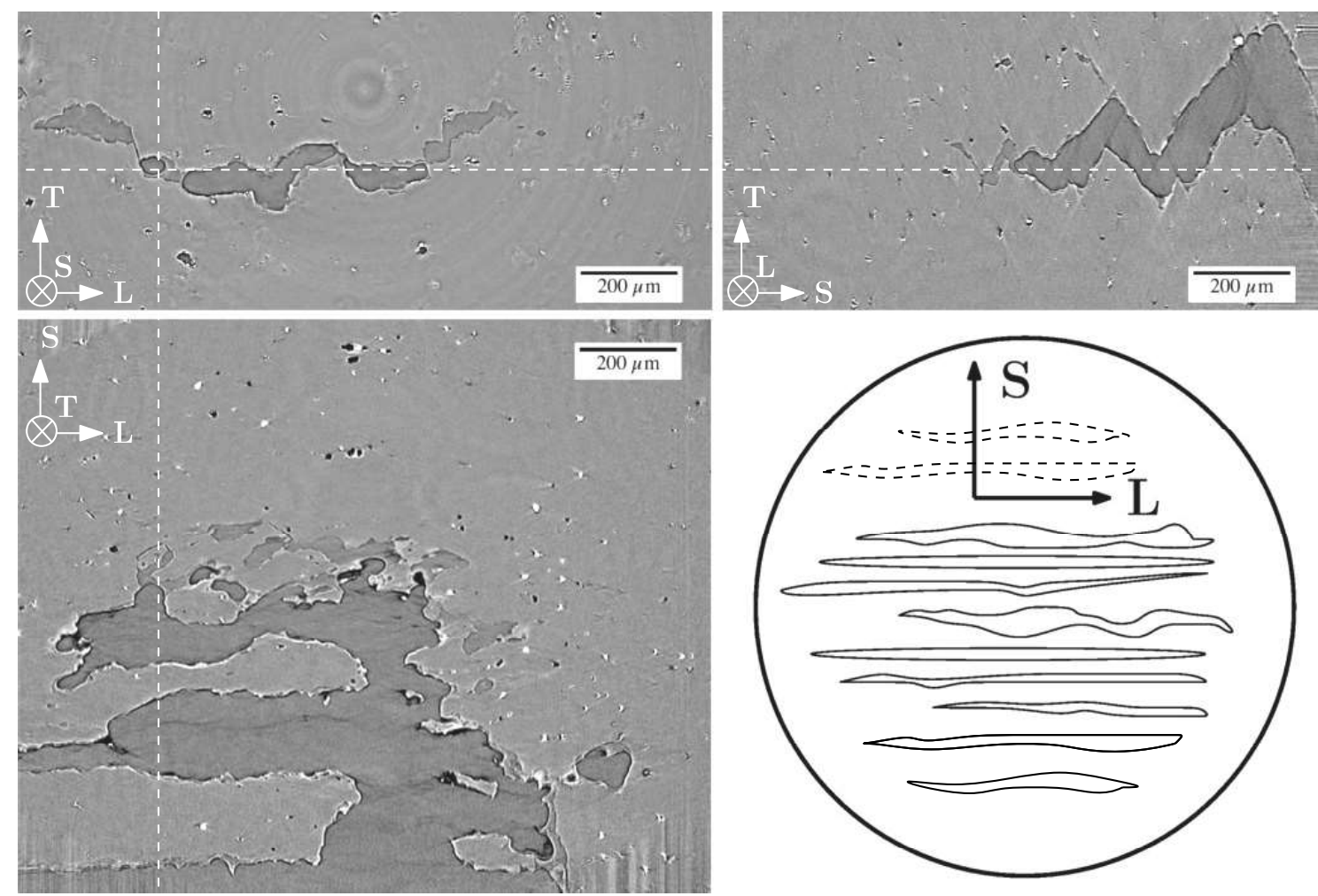

Figure 10: Orthographic projection of the same macro-crack in the Central-Scan of the RN10 bar, and schematics (bottom right) showing the location and topology of cracks in a top-view $2 \mathrm{D}$ section of the notch.

To acquire a better understanding of the topography of fracture surfaces in notched bars, such as those observed in [1,2], particular reconstructions of 2D images in $\mathrm{T}-\mathrm{L}$ views were made so as to provide three orthogonal views of the cracks. The result is illustrated in Fig. 10 for the central scans. From the top view (L-S section) three macrocracks can clearly be observed (bottom-left in figure). These cracks, which are narrow and extended parallel to the $\mathrm{L}$ direction, must have formed independently of each other. The average midlineto-midline distance between them is $300 \mu \mathrm{m}$ along $\mathrm{S}$. The schematic in Fig. 10 (bottomright) illustrates the fact that the macrocracks predominately form in the central region of the RN10 specimen. Each macrocrack essentially propagates along the L direction of the 
material.

It must be emphasized that the three cracks shown in the L-S section (bottom-left in Fig. 10) are actually linked together, but not in the plane of view. The linkup between them can be clearly seen in the rendering of the $\mathrm{T}-\mathrm{S}$ view (top right in Fig. 10). Interestingly, this view shows that the trace of the 3 -crack ensemble in this plane forms a zig-zag pattern. This pattern is quite similar to crack topography in anisotropic steels [38] and can be explained simply as follows. In the inter-crack ligaments seen in the top view ( $\mathrm{L}-\mathrm{S}$ section) prevails a near plane strain state, which is conducive to shear localization. Hence, the most likely formation mechanism of the three-crack ensemble is as follows: (i) void coalescence first occurs along the L direction leading to formation of cracks extended along L; (ii) multiple such macrocracks independently form in parallel T-L planes; (iii) the cracks linkup in shear in $\mathrm{T}-\mathrm{S}$ planes thus giving rise to the zig-zag pattern.

\subsection{State of damage in the RN2 specimen}

The bar with a sharp notch (RN2 specimen) was deformed to a nominal strain of $\Delta \phi_{S} / \phi_{0}=0.06$. Observations throughout the central scans of the RN2 bar suggest that damage is extensive, as illustrated in Fig. 11. The main difference with the RN10 bar is that damage manifests here in the form of microcracks and flat voids. In other words, void blunting is not as effective as in the RN10 bar (compare for instance Fig. 11 with Fig. 5). Many voids nucleate on second phase particles, but the sharper microcracks do not seem to be associated with particles. It is likely that such microcracks are twin-sized voids, although their orientation is generally normal to the major tensile stress (vertical in Fig. 11). Strain localization induced by formation of $\{10 \overline{1} 1\}$ contraction and $\{10 \overline{1} 1\}-\{10 \overline{1} 2\}$ double twins can lead to formation of microcracks $[29,43]$. Irrespective of how they nucleated, all microcracks appear as independent units (Fig. 11a), at incipient coalescence along L (Fig. 11b) or as part of a macrocrack (Fig. 11c).

Fig. 12 illustrates details of how flat voids/microcracks link-up in the RN2 specimen. Blunted microcracks that happen to be at about the same height coalesce by an internal necking type mechanism (e.g. the 3-5 right-most voids in Fig. 12d). Otherwise, they link-up via a shear-like mechanism.

In the RN2 bar, macrocracks seem to form preferentially near the circumference, somewhat extended along L, as schematically shown in Fig. 13 (bottom right). This topography can be ascertained by making three orthogonal sections within the Surface-Scans. Each macrocrack is "horizontal" in the T-L section (top-left) but appears to zig-zag in the T-S plane (top-right). The L-S view of the minimum cross section (bottom-left), illustrates that macrocracks in the RN2 bar form near the free surface and grow along the L direction.

\subsection{Quantitative analysis}

Following the procedure described in Section 2.3 the apparent in-plane dimensions of about 1000 voids or microcracks were determined in each bar. The frequency distributions of both the width, $d$, and height, $h$, are reported in Fig. 14. Accordingly, the (in-plane) void aspect ratio distribution is also obtained with $W=h / d$. Irrespective of their origin, voids and microcracks blunt to various degrees depending on factors such as spatial distribution, 


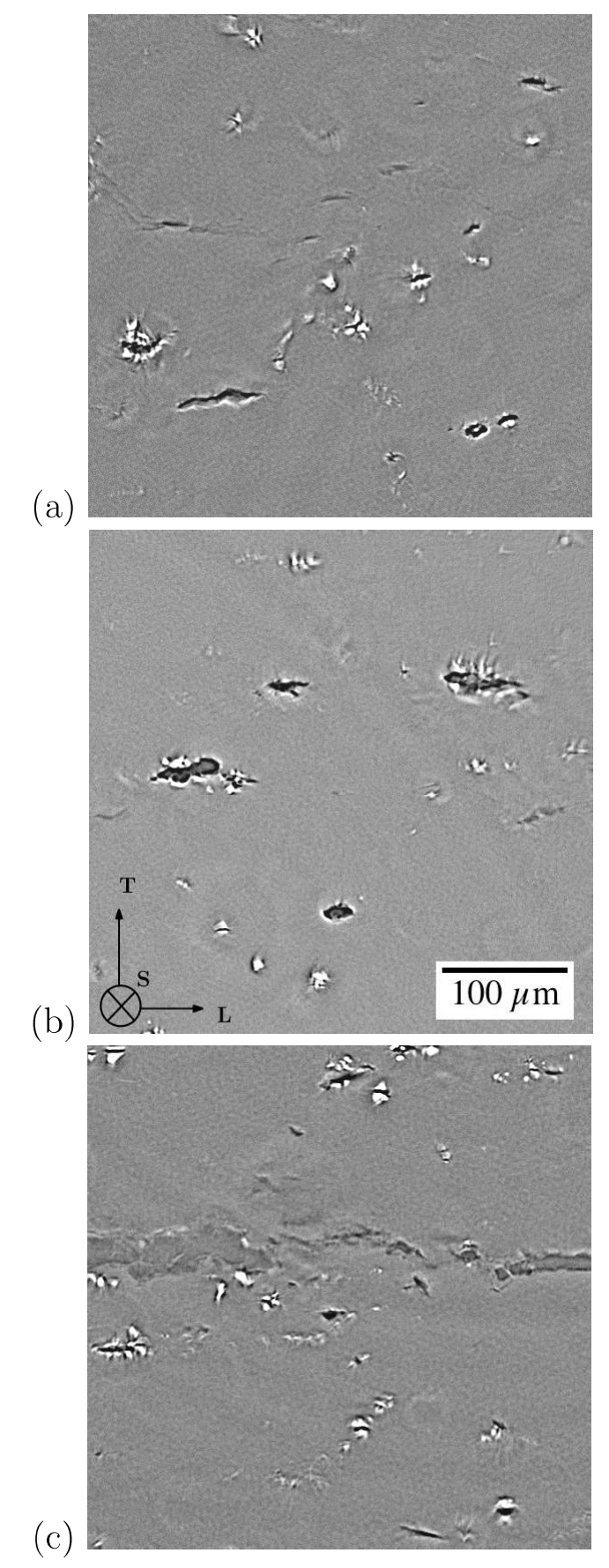

Figure 11: Reconstructed micrographs of the Central-Scans showing diffuse damage in the RN2 specimen deformed to $\Delta \phi_{S} / \phi_{0}=0.06$. Microcracks and flat voids are dominant features.

local triaxiality and strain level. Since spatial variations of stress triaxiality in a given notch geometry are still lower than mean differences in triaxiality between the two types of specimens, average values of various void attributes can be quite informative. In the 

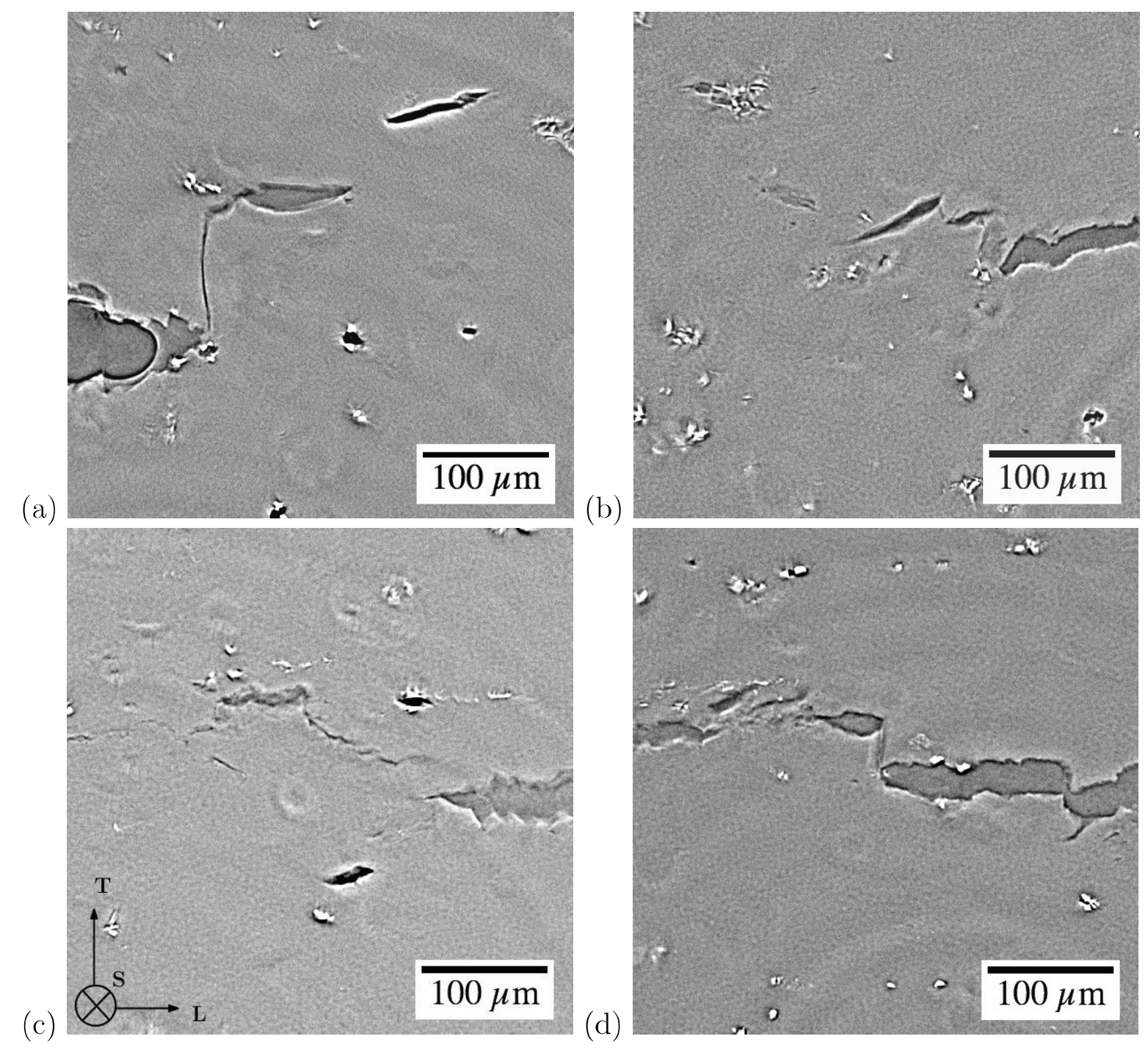

(b)

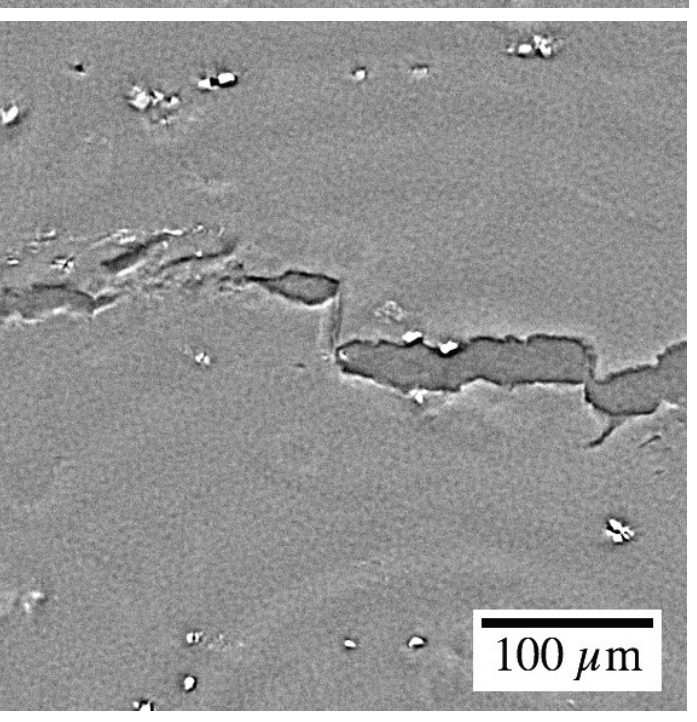

Figure 12: Void/microcrack link-up via micro-scale localization in the Surface-Scans of the RN2 specimen.

RN10 bar, 1089 voids/microcracks were analyzed. The average width and height of the measured voids are $\bar{d}=12.4 \mu \mathrm{m}$ and $\bar{h}=6.7 \mu \mathrm{m}$, respectively. Thus, an estimate of the average void aspect ratio is $\bar{h} / \bar{d}=0.54$, compare with $\bar{W}=0.62$ from Fig. $14 \mathrm{e}$. In the RN2 bar, averages over a population of 949 voids/microcracks were found to be $\bar{d}=12.0 \mu \mathrm{m}$, $\bar{h}=4.4 \mu \mathrm{m}$ (thus $\bar{h} / \bar{d}=0.37$ ) and $\bar{W}=0.48$. These results suggest that the extent of void blunting is different in the RN10 and RN2 bars. This can be attributed to the difference in the average triaxiality prevailing in each specimen. It is documented that voids elongate more at lower stress triaxiality, irrespective of initial state $[3,14,20]$.

Based on the same measurements and the elliptical void approximation, the average void area fraction was found to be $\sim 0.012$ and $\sim 0.007$ in the RN10 and RN2 bars, respectively. Although the analyzed area is somewhat larger in the RN2 bar and the extent of damage is 

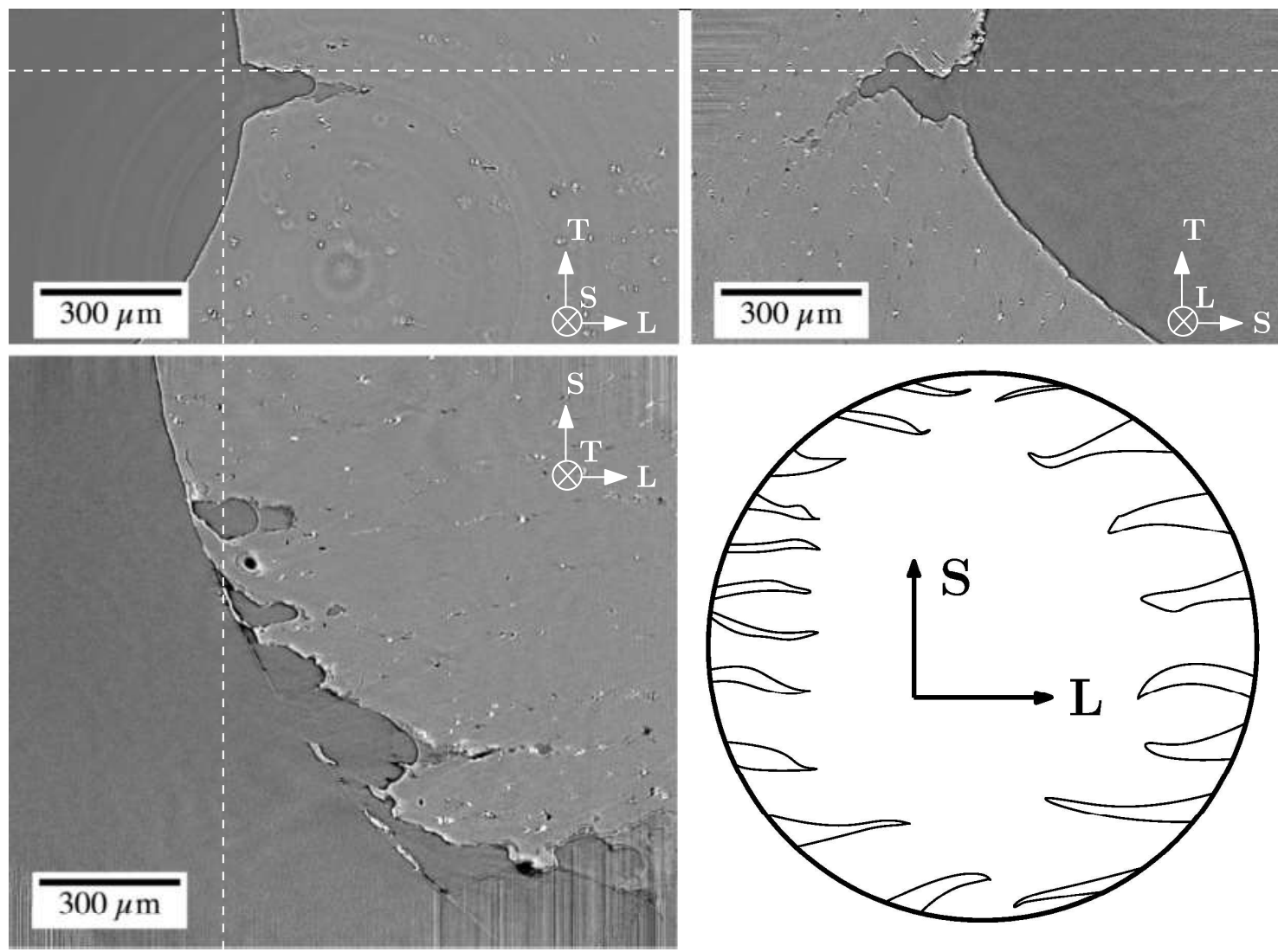

Figure 13: Orthographic projection of macro-cracks in the Surface-Scan of the RN2 bar, and schematics (bottom right) showing the location and topology of cracks in a top-view 2D section of the notch.

less distributed therein, its lower porosity may be attributed to the limited void blunting, as suggested by qualitative observations and the quantitative measurements in Fig. 14.

While average quantities are useful in obtaining trends, extrema are also worth analyzing. For instance, there is a greater population of flat microvoids in the RN2 bar. For example, over 100 voids fall into the $W=0.2$ bin in the RN2 bar (Fig. 14f); compare with about 30 in the RN10 bar (Fig. 14e). The situation may, in fact, be more extreme than that because determining the height of microcracks is inevitably entailed with greater uncertainty and even falls beyond the resolution of tomography below the micron. Note that no data is reported for voids thinner than $1 \mu \mathrm{m}$. Table 1 summarizes some key features of the quantitative data in Fig. 14.

\section{Discussion}

As in previous work [2, 15], round notched specimens have been used to generate an effective "damage process zone" in work-hardened, partially annealed Mg alloy AZ31. Two specimens (blunt and sharp notches) were deformed to fracture and two more were deformed 
(a)

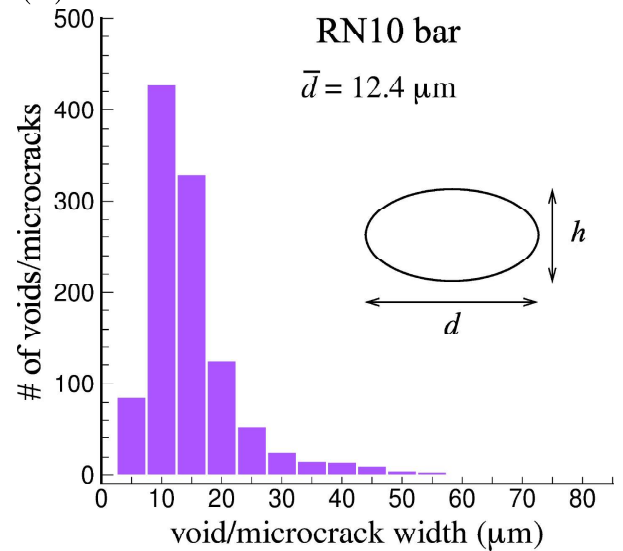

(c)

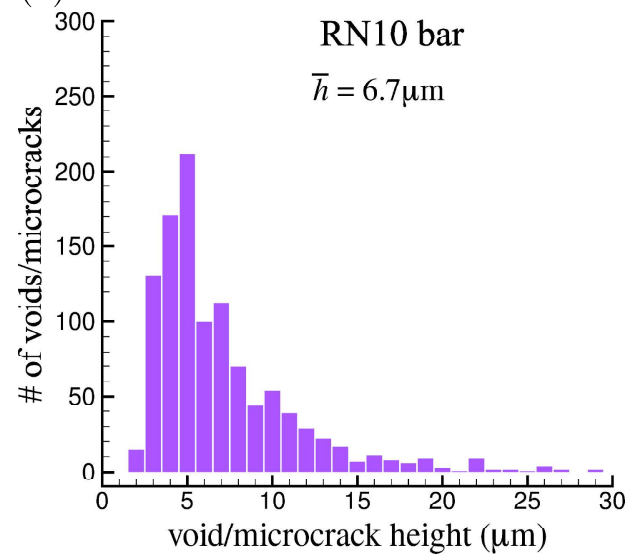

(e)

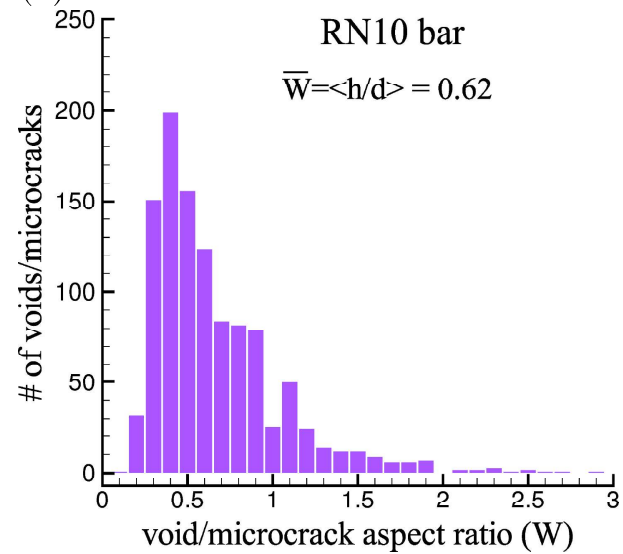

(b)

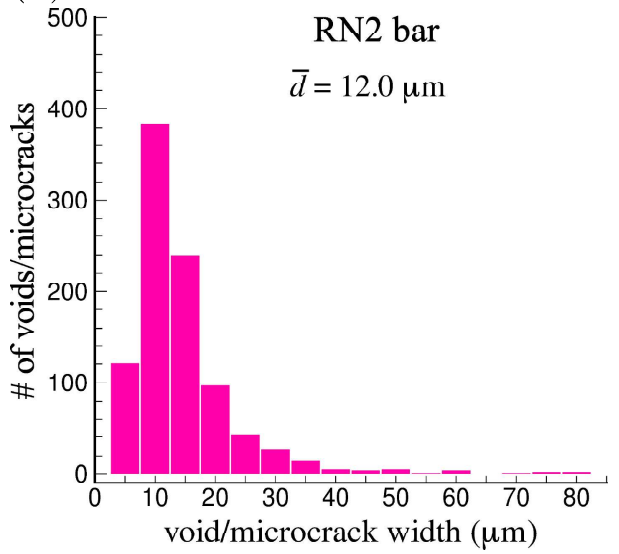

(d)

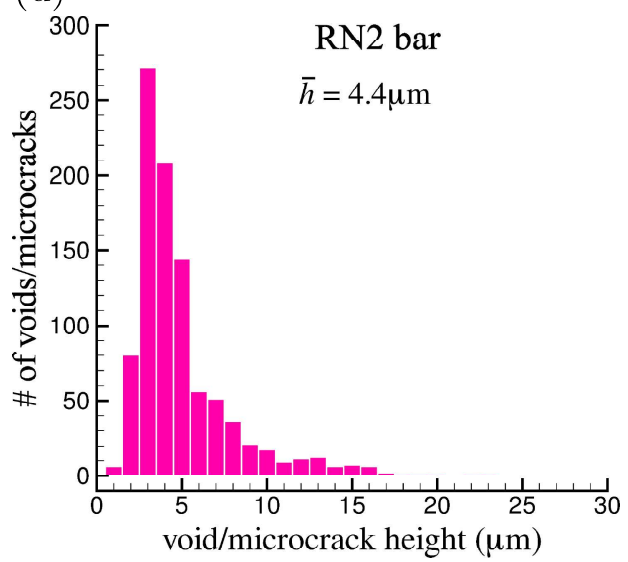

(f)

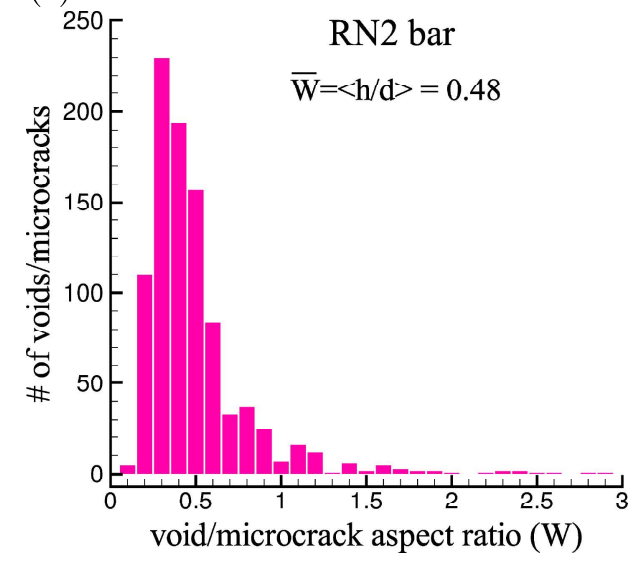

Figure 14: Frequency distributions of in-plane void width, $d$, height, $h$, and aspect ratio, $W$, in the RN10 bar (left) and RN2 bar (right).

past the peak load to be observed ex situ using synchrotron radiation laminography. The experimental procedure was successful on two counts. First, instability induced failure was 
Table 1: Averages of width, height and aspect ratio of about $\sim 1000$ voids and micro-cracks analyzed per specimen at incipient cracking. $N$ is the number of voids with aspect ratio $W \leq 0.2$.

\begin{tabular}{l|ccccc} 
Specimen & $\bar{d}(\mu \mathrm{m})$ & $\bar{h}(\mu \mathrm{m})$ & $\bar{h} / \bar{d}$ & $\bar{W}$ & $N$ \\
\hline RN10 & 12.4 & 6.7 & 0.54 & 0.62 & 32 \\
RN2 & 12.0 & 4.4 & 0.37 & 0.48 & 110
\end{tabular}

avoided. Second, the assumption that the bars were deformed to incipient cracking was confirmed a posteriori. In turn, there was much to see in the damage process zone. Thus, even with ex situ observations, tomography has been utilized to great potential.

Considering a single state per specimen in ex situ tomography has not limited much the extent of information obtained regarding the process of damage accumulation. For reasons elaborated upon in previous work based on destructive characterization of damage $[38,44,45]$, gradients in key fields, such as plastic strain and stress triaxiality, enabled the genesis of void growth to coalescence, as well as that of crack initiation and propagation to be elucidated. Indeed, voids, micro- and macro-cracks were observed at many stages of the damage process based on their spatial location. Furthermore, tomography-enabled access to 3D information provided much better statistics over a much larger volume than by serial sectioning.

A key finding of this research is that damage in AZ31 is quite diffuse in the specimens. This is an essential difference with previous tomographic observations in $\operatorname{Mg}$ alloys $[6,7,23]$ because of the thin sheet limitation and associated shear localization dominated fracture. Damage occurs by extensive void nucleation, growth and coalescence. At incipient cracking in either specimen analyzed, void growth is more significant in the blunt notched specimen with a lower average triaxiality ${ }^{1}$. The qualitative observations (compare Fig. 5 with Fig. 11) as well as the measured average in-plane porosities and void aspect ratios in Section 3.3 support that.

Void nucleation at second phase particles appears to be an important mechanism for damage initiation in AZ31 either by cracking, Fig. 8, or decohesion, which is often one-sided, Fig. 5. This finding is consistent with the observations in [2]. Based on their microstructural analyses, the large faceted particles contain Mn (e.g., Al-Mn and Mg-Mn particles) and the irregularly shaped ones are $\beta-\mathrm{Mg}_{17} \mathrm{Al}_{12}$ particles. The role of second-phase particles in the mechanical behavior of metallic materials has long been known (see [40] for a recent review) but remains under-appreciated in the literature concerned with $\mathrm{Mg}$ alloys.

In a mechanistic model of ductility due to Barnett $[4,47]$ twinning induced microcracking is viewed as the sole damage process. This mechanism is mostly relevant to high-purity magnesium or when conditions for effective nucleation at second phases are not met, for

\footnotetext{
${ }^{1}$ Void growth theory predicts that the rate of growth of porosity is faster at higher stress triaxiality. This does not necessarily entail that the porosity at failure is larger at higher triaxiality; see e.g. [46].
} 
example at very low stress triaxiality $[4,47,48]$. In a microtomography analysis of pure magnesium [23], flat twin-related voids indeed formed the major portion of accumulated damage. The relatively low critical nucleation strain of these voids $(\sim 0.1)$ has led to the view that damage and fracture are controlled by twin-related voids or microcracks [23], in keeping with other work in the literature [4, 49], which in fact was limited to uniaxial loading conditions and shear-like fracture. On the other hand, in alloys with second phase particles, the increasing number of cracked particles with strain reveals their important role in damage accumulation [32]. Also, the presence of second phase particles on a dimpled fracture surface of notched AZ31 confirms their role in ductile fracture [2, 50]. Interestingly, even in experiments where fracture is induced by plastic instability in shear, the largest voids are those originating from particles [7]. Therefore, it would be fair to say that the competition between various void nucleation mechanisms in $\mathrm{Mg}$ alloys, with twinning being one possible origin, deserves to be studied further.

Void growth has also been documented here. It occurs to various extents depending on triaxiality, nucleation mechanism as well as the relative proximity of nucleation sites. Damage is often observed to initiate as flat micro-voids, irrespective of nucleation mechanism. These microvoids blunt more at low triaxiality (RN10 bar), as documented in Fig. 14. In many instances, micro-crack blunting is found to be limited so that at incipient fracture most voids are still quite flat on average. This holds near the notch root (Fig. 6), but the observation holds pervasively in the sharply notched specimen (Figs. 11 and 12). In the RN2 bars, void coalescence takes place at much lower plastic strains, and this limits the extent of void blunting prior to crack initiation.

These observations have potential implications on modeling ductile fracture in AZ31, and possibly other $\mathrm{Mg}$ alloys. Finite element micromechanical cell model calculations with penny-shape cracks in plastically anisotropic matrices [51] predict a much faster opening/blunting of the micro-cracks than observed or measured in this study. This discrepancy merits further attention and invites more refined studies of void growth in $\mathrm{Mg}$ alloys, paying particular attention to crystallographic aspects $[12,52,53]$. This in turn may help address different growth mechanisms depending on the initiation process and contribution of glide and twinning deformation systems. The idea of a slower-than-expected opening of the micro-cracks was recently utilized by Kondori and Benzerga [46] in modeling the triaxialitydependent ductility of a rare-earth based alloy. Our present observations for AZ31 suggest that a similar approach may be followed for this material, in the absence of a more refined model that incorporates crystallographic aspects of void mediated failure.

Void coalescence by internal necking has also been observed, quite frequently at the center of the RN10 bar, e.g., Fig. 5. To our knowledge, such observations using non-destructive techniques are documented for the first time in $\mathrm{Mg}$ alloys. We observed the typical "knifeedge" material separation [54] (Fig. 5a), as well as various stages of internal necking of the intervoid ligament (note that the process in Fig. $5 \mathrm{c}$ is well underway between the largest two cavities). When void blunting was limited, instances of coalescence by micro-shears or brittle cracking of the intercrack ligament have also been observed.

From the present tomography analyses new insight is gained in what concerns the topography of incipient macroscopic cracks, and ultimately the topography of fracture surfaces in 
post mortem observations [2]. In the specimen with a blunt notch, the largest macroscopic crack has a corrugated shape, Fig. 10. The corrugation results in a zig-zag appearance in the T-S plane. Reconstructing the genesis of formation of this type of crack is rather straightforward, although in situ real time observations would make this more clear. The fact that other isolated macrocracks are observed, extended along the rolling (L) direction, clearly shows that crack growth is essentially driven along that direction. Shear localization then occurs between two such parallel cracks. As the process is repeated multiple times, it leads to the corrugated character of a larger crack. When the latter approaches the free surfaces, final loss of load bearing capacity occurs through shear lip formation, Fig. 9f.

It is worth noting that the process of formation of the "corrugated crack" in Fig. 10 may be far more common than currently conceived in the ductile fracture literature. The "zigzagging" of ductile cracks discussed by various authors, eventually settled in the analyses of cup-cone fracture [55], is not inherent to the process of crack propagation, at least not in round bars. Indeed, if zig-zagging were to hold in every meridian plane the fully formed cracks would be a sequence of annuli of hills and valleys. This topography has simply never been observed in any fracture surface. The fact is, while the loading is axially symmetric plastic flow may not and, more importantly, the microstructural defects that mediate void nucleation and growth are not either. Void coalescence is a directional process, and this leads to preferred crack growth directions, that is cracks that are well extended in one direction but not necessarily much in the other transverse direction. Obviously, such inherent anisotropy is greater in some materials than others. It is definitely present in the AZ31 alloy studied here, probably because of the proximity of second-phase particles in processing-induced linear clusters aligned along $\mathrm{L}$. This type of anisotropy was also observed in steels containing stringers of particles, such as sulfides (see for instance Fig. 10 in [38]).

The tomography analyses have also confirmed essential differences between the blunt and sharp notches, as previously discussed by Kondori [56]. Ductile fracture is generally driven by plastic strain and stress triaxiality. In round notched bars, the stress triaxiality is maximum at the center but the plastic strain is maximum at the notch root in the early stages of deformation. This holds when crystallographic aspects are taken into account, as recently analyzed by Selvarajou et al. $[8,9]$. In ductile metals, crack initiation usually occurs at the center, either as a sign that triaxiality dominates over plastic strain, or after the plastic strain maximum has moved away from the notch root. This competition between triaxiality-driven or plastic-strain-driven crack initiation has been well studied by means of computations. For instance, crack initiation has been simulated at the notch root in plane strain notched bars [57], consistent with experimental observations. However, in round notched bars crack initiation at the notch root is not so common. This makes AZ31, and probably other $\mathrm{Mg}$ alloys, quite different. In the present study, the situation of profuse cracking at the notch root is illustrated in Fig. 13 for the specimen with a sharp notch. Whether crack initiation occurs on the surface or slightly away from it cannot be ascertained in ex situ observations. It is indeed possible that void initiation occurs away from the surface then the incipient void links up with the surface. The notch-acuity mediated transition in the location of crack initiation from the center to the surface presents challenges for modeling fracture in $\mathrm{Mg}$ alloys. This aspect, in turn, may serve as basis to discriminate among ductile 
fracture models.

Crystallographic aspects of void growth and coalescence merit further attention. This is needed not only to investigate the limited blunting of microcracks, as noted above, but also to study faceted void growth, directional coalescence, interaction with grain boundaries as well as aspects of crack initiation and growth. Faceted void growth in metallic alloys with a hexagonal crystal structure have been studied in the past [52] but more refined analyses are needed in Mg alloys. Recent micromechanical analyses, e.g. [12, 53], are promising but are limited to idealized cylindrical voids. Yet, Prasad et al. [12] have discussed for instance a competition between plasticity driven void enlargement to coalescence ahead of the crack tip and shear banding, sometimes shielding the crack/notch tip, depending on crystal orientation. Another aspect suggested by the quantitative measurements is that the average width of voids in both bars is $\sim 12 \mu \mathrm{m}$ (Fig. 14a,b), which is the average grain size for the largest population of grains. Whether this observation is fortuitous or hints at grain-boundary arrest of void growth would deserve further analysis, which indeed requires that crystallographic aspects be considered.

What is of particular importance is that ductile damage is found to be diffuse throughout the specimens. This emphasizes a conclusion drawn by Kondori and Benzerga [2], namely that $\mathrm{Mg}$ alloy $\mathrm{AZ31}$, and probably other $\mathrm{Mg}$ alloys, are capable of dissipating significant amounts of energy prior to rupture. Observations such as limited microcrack blunting, crack initiation at a sharp notch, thin shear lips, and shear-like fractures are all indications of intrinsic quasi-brittleness. However, such attributes are common to technologically important aluminum alloys and some high strength steels. When micro-cracking occurs, it is quite profuse and the overall deformation to fracture remains significant. Shear fractures, in particular, are important to mitigate against in processing or basic material characterization. However, they should not be mistaken for lack of intrinsic ductility. Indeed, when a damage process zone develops significant energy dissipation is mediated by void nucleation and growth to coalescence, just like in other tough and ductile metallic materials. It is important for the accelerated development of $\mathrm{Mg}$ alloys in practical applications that further studies be carried out on other materials systems. This work has shown that micro-computed tomography is a powerful tool in pursuing this research agenda, provided appropriate specimens are employed.

\section{Concluding Remarks}

Synchrotron radiation laminography has been used to study the state of damage in $\mathrm{Mg}$ alloy AZ31. The salient features, which likely apply to various other Mg alloys are as follows:

1. Damage is diffuse and not localized. This indicates ductile behavior. Processes of void formation and growth to coalescence are pervasive. Damage initiates in the form of flat voids that blunt to various extents depending on spatial location, overall triaxiality and local strain levels.

2. The transition from damage to fracture occurs by formation of macroscopic cracks due to directional void coalescence in the rolling direction of the plate. When multiple 
parallel macrocracks eventually form away from the notch root, the macroscopic crack develops into a corrugated crack with irregular thickness.

3. In bars with a blunt notch, cracks are located about the center of the specimen. In bars with a sharp notch, they are located near the notch root.

4. Up to macroscopic crack initiation, the blunting of microvoids and microcracks occurs at a rate slower than predicted using available continuum analyses of void growth. This, along with potentially faceted void growth, directional coalescence and interaction with grain boundaries, warrant crystallographic aspects of damage progression to be examined further at higher spatial resolutions.

\section{Acknowledgments}

AAB is grateful for the support provided by the National Science Foundation under Grant Number CMMI-1563580 (Program Director: Dr. Alexis Lewis). The authors acknowledge the European Synchrotron Research Facility for provision of beamtime during user experiment MA-2032, and Dr. Yin Cheng for help with the experiment.

\section{References}

[1] B. Kondori, A. A. Benzerga, Fracture strains, damage mechanisms and anisotropy in a magnesium alloy across a range of stress triaxialities, Experimental Mechanics 54 (2014) 493-499.

[2] B. Kondori, A. A. Benzerga, Effect of Stress Triaxiality on the Flow and Fracture of Mg Alloy AZ31, Metallurgical and Materials Transactions A. 45 (2014) 3292-3307.

[3] A. Pineau, A. A. Benzerga, T. Pardoen, Failure of metals I. Brittle and Ductile Fracture, Acta Materialia 107 (2016) 424-483.

[4] M. R. Barnett, Twinning and the ductility of magnesium alloys Part II. "contraction" twins, Materials Science and Engineering: A 464 (2007) 8-16.

[5] D. Ando, J. Koike, Y. Sutou, Relationship between deformation twinning and surface step formation in AZ31 magnesium alloys, Acta Materialia 58 (2010) 4316-4324.

[6] D. Steglich, T. Morgeneyer, Failure of magnesium sheets under monotonic loading: 3D examination of fracture mode and mechanisms, International Journal of Fracture 183 (2013) 105-112.

[7] A. K. Ray, D. S. Wilkinson, The effect of microstructure on damage and fracture in AZ31B and ZEK100 magnesium alloys, Materials Science and Engineering A 658 (2016) 33-41.

[8] B. Selvarajou, B. Kondori, A. A. Benzerga, S. P. Joshi, On Plastic Flow in Notched Hexagonal Close Packed Single Crystals, Journal of the Mechanics and Physics of Solids 94 (2016) 273-297.

[9] B. Selvarajou, S. P. Joshi, A. A. Benzerga, Three dimensional simulations of texture and triaxiality effects on the plasticity of magnesium alloys, Acta Materialia 127 (2017) 54-72.

[10] V. Kaushik, R. Narasimhan, R. Mishra, Experimental study of fracture behavior of magnesium single crystals, Materials Science and Engineering: A 590 (2014) 174-185.

[11] N. S. Prasad, N. Naveen Kumar, R. Narasimhan, S. Suwas, Fracture behavior of magnesium alloys role of tensile twinning, Acta Materialia 94 (2015) 281-293.

[12] N. S. Prasad, R. Narasimhan, S. Suwas, Effects of lattice orientation and crack tip constraint on ductile fracture initiation in mg single crystals, International Journal of Plasticity 97 (2017) 222-245.

[13] N. S. Prasad, R. Narasimhan, S. Suwas, Effect of notch acuity on the fracture behavior of AZ31 Mg alloy, Engineering Fracture Mechanics 187 (2018) 241-261.

[14] A. A. Benzerga, J.-B. Leblond, Ductile fracture by void growth to coalescence, Advances in Applied Mechanics 44 (2010) 169-305. 
[15] B. Kondori, A. A. Benzerga, On the notch ductility of a magnesium-rare earth alloy, Materials Science and Engineering: A 647 (2015) 74-83.

[16] S. R. Stock, Recent advances in X-ray microtomography applied to materials, International Materials Reviews 53 (2008) 129-181.

[17] E. Maire, P. Withers, Quantitative X-ray tomography, Inter. Mater. Rev. 59 (2014) 1-43.

[18] J.-Y. Buffière, E. Maire, P. Cloetens, G. Lormand, R. Fougères, Characterization of internal damage in a MMCp using X-ray synchrotron phase contrast microtomography, Acta Materialia 47 (1999) 16131625.

[19] L. Babout, Y. Bréchet, E. Maire, R. Fougères, On the competition between particle fracture and particle decohesion in metal matrix composites, Acta Materialia 52 (2004) 4517-4525.

[20] A. Weck, D. S. Wilkinson, E. Maire, H. Toda, Visualization by X-ray tomography of void growth and coalescence leading to fracture in model materials, Acta Materialia 56 (2008) 2919-2928.

[21] T. F. Morgeneyer, M. J. Starink, I. Sinclair, Evolution of voids during ductile crack propagation in an aluminium alloy sheet toughness test studied by synchrotron radiation computed tomography, Acta Materialia 56 (2008) 1671-1679.

[22] H. Pommier, E. P. Busso, T. F. Morgeneyer, A. Pineau, Local approach to stress relaxation cracking in a AISI 316l-type austenitic stainless steel: Tomography damage quantification and FE simulations, Engineering Fracture Mechanics 183 (2017) 170-179.

[23] M. J. Nemcko, D. S. Wilkinson, On the damage and fracture of commercially pure magnesium using x-ray microtomography, Materials Science and Engineering A 676 (2016) 146-155.

[24] N. Thomas, J. S. Herrington, A. A. Benzerga, Plastic flow anisotropy drives shear fracture, Submitted.

[25] L. Helfen, T. Baumbach, P. Mikulík, D. Kiel, P. Pernot, P. Cloetens, J. Baruchel, High-resolution three-dimensional imaging of flat objects by synchrotron-radiation computed laminography, Applied Physics Letters 86 (2005) 071915.

[26] D. J. Bull., S. M. Spearing, I. Sinclair, L. Helfen, Three-dimensional assessment of low velocity impact damage in particle toughened composite laminates using micro-focus x-ray computed tomography and synchrotron-radiation laminography, Composites Part A 52 (2013) 62-69.

[27] T. F. Morgeneyer, L. Helfen, I. Sinclair, H. Proudhon, F. Xu, T. Baumbach, Ductile crack initiation and propagation assessed via in situ synchrotron radiation computed laminography, Scripta Mat. 65 (2011) 1010-1013.

[28] T. F. Morgeneyer, L. Helfen, H. Mubarak, F. Hild, 3D digital volume correlation of synchrotron radiation laminography images of ductile crack initiation: An initial feasibility study, Experimental Mechanics 53 (2013) 543-556.

[29] J. Koike, Enhanced deformation mechanisms by anisotropic plasticity in polycrystalline Mg alloys at room temperature, Metallurgical and Materials Transactions A. 36A (2005) 1689-1696.

[30] D. Ando, J. Koike, Y. Sutou, The role of deformation twinning in the fracture behavior and mechanism of basal textured magnesium alloys, Materials Science and Engineering: A 600 (2014) 145-152.

[31] J. J. Bhattacharyya, F. Wang, P. J. McQuade, S. R. Agnew, Deformation and fracture behavior of mg alloy, WE43, after various aging heat treatments, Materials Science and Engineering: A 705 (2017) 79-88.

[32] M. Lugo, M. A. Tschopp, J. B. Jordon, M. F. Horstemeyer, Microstructure and damage evolution during tensile loading in a wrought magnesium alloy, Scripta Materialia 64 (2011) 912-915.

[33] S. Basu, E. Dogan, B. Kondori, I. Karaman, A. A. Benzerga, Towards Designing Anisotropy for Ductility Enhancement: A Theory-Driven Investigation in Mg-alloys, Acta Materialia 131 (2017) 349-362.

[34] T. Weitkamp, P. Tafforeau, E. Boller, P. Cloetens, J. P. Valade, P. Bernard, F. Peyrin, W. Ludwig, L. Helfen, J. Baruchel, Parallel-beam imaging at the ESRF beamline ID19: current status and plans for the future, Vol. 1234 of Proceedings SRI 2009, AIP Conference Proceedings, 2010, pp. 83-86.

[35] L. Helfen, T. Baumbach, P. Cloetens, J. Baruchel, Phase-contrast and holographic computed laminography, Applied Physics Letters 94 (2009) 104103.

[36] A. Myagotin, A. Voropaev, L. Helfen, D. Hanschke, T. Baumbach, Efficient volume reconstruction for parallel-beam computed laminography by filtered backprojection on multi-core clusters., IEEE Trans- 
actions on Image Processing 22 (12) (2013) 5348-5361.

[37] P.-A. Douissard, A. Cecilia, X. Rochet, X. Chapel, T. Martin, T. van de Kamp, L. Helfen, T. Baumbach, L. Luquot, X. Xiao, J. Meinhardt, A. Rack, A versatile indirect detector design for hard X-ray microimaging, Jounal of Instrumentation 7 (2012) P09016.

[38] A. A. Benzerga, J. Besson, A. Pineau, Anisotropic ductile fracture. Part I: experiments, Acta Materialia 52 (2004) 4623-4638.

[39] A. A. Benzerga, J. Besson, A. Pineau, Anisotropic ductile fracture. Part II: theory, Acta Materialia 52 (2004) 4639-4650.

[40] Huang, K. and Marthinsen, K. and Zhao, Q. and Logé, R. E., The double-edge effect of second-phase particles on the recrystallization behaviour and associated mechanical properties of metallic materials, Progress in Materials Science 92 (2018) 284-359.

[41] A. A. Benzerga, Micromechanics of Coalescence in Ductile Fracture, Journal of the Mechanics and Physics of Solids 50 (2002) 1331-1362.

[42] A. A. Benzerga, J.-B. Leblond, Effective Yield Criterion Accounting for Microvoid Coalescence, Journal of Applied Mechanics 81 (3) (2014) 031009.

[43] M. Lentz, M. Risse, N. Schaefer, W. Reimers, I. J. Beyerlein, Strength and ductility with $\{10 \overline{1} 1\}-\{10 \overline{1} 2\}$ double twinning in a magnesium alloy, Nature Communications 7 (2016) 11068.

[44] A. S. Argon, J. Im, R. Safoglu, Cavity Formation from Inclusions in Ductile Fracture, Metallurgical Transactions A. 6A (1975) 825-837.

[45] F. M. Beremin, A. Pineau, F. Mudry, J. Devaux, Y. D'Escatha, P. Ledermann, Cavity formation from inclusions in ductile fracture, Metallurgical Transactions A. 12A (1981) 723-731.

[46] B. Kondori, A. A. Benzerga, Modeling damage accumulation to fracture in a magnesium-rare earth alloy, Acta Materialia 124 (2017) 225-236.

[47] M. R. Barnett, Twinning and the ductility of magnesium alloys Part I: "tension" twins, Materials Science and Engineering: A 464 (2007) 1-7.

[48] A. K. Rodriguez, G. Ayoub, B. Mansoor, A. A. Benzerga, Effect of strain rate and temperature on fracture of AZ31B magnesium alloy, Acta Materialia 112 (2016) 194-208.

[49] S. Niknejad, S. Esmaeili, N. Y. Zhou, The role of double twinning on transgranular fracture in magnesium AZ61 in a localized stress field, Acta Materialia 102 (2016) 1-16.

[50] M. Marya, L. G. Hector, R. Verma, W. Tong, Microstructural effects of AZ31 magnesium alloy on its tensile deformation and failure behaviors, Materials Science and Engineering: A 418 (2006) 341-356.

[51] S. M. Keralavarma, S. Hoelscher, A. A. Benzerga, Void growth and coalescence in anisotropic plastic solids, International Journal of Solids and Structures 48 (2011) 1696-1710.

[52] J. Crépin, T. Bretheau, D. Caldemaison, Cavity growth and rupture of $\beta$-treated zirconium: A crystallographic model, Acta Materialia 44 (1996) 4927-4935.

[53] N. S. Prasad, R. Narasimhan, S. Suwas, Numerical simulations of cylindrical void growth in Mg single crystals, International Journal of Fracture 200 (2016) 159-183.

[54] A. A. Benzerga, J. Besson, A. Pineau, Coalescence-Controlled Anisotropic Ductile Fracture, Journal of Engineering Materials and Technology 121 (1999) 221-229.

[55] V. Tvergaard, A. Needleman, Analysis of the cup-cone fracture in a round tensile bar, Acta Metallurgica 32 (1984) 157-169.

[56] B. Kondori, Ductile fracture of magnesium alloys: characterization and modeling, Ph.D. thesis, Texas A\&M University, USA (2015).

[57] A. Needleman, V. Tvergaard, An analysis of ductile rupture in notched bars, Journal of the Mechanics and Physics of Solids 32 (1984) 461-490. 